\title{
Pure awareness experience
}

\section{Brentyn J. Ramm}

To cite this article: Brentyn J. Ramm (2023) Pure awareness experience, Inquiry, 66:3, 394-416, DOI: 10.1080/0020174X.2019.1592704

To link to this article: https://doi.org/10.1080/0020174X.2019.1592704

曲 Published online: 19 Mar 2019.

Submit your article to this journal $₫$

Џll Article views: 773

Q View related articles $\sqsubset$

View Crossmark data $\nearrow$ 


\title{
Pure awareness experience
}

\author{
Brentyn J. Ramm a,b \\ ${ }^{\mathrm{a}}$ School of Philosophy, The Australian National University, Canberra, Australia; ${ }^{\mathrm{b}}$ Department of \\ Philosophy, The Ohio State University, Columbus, $\mathrm{OH}$, USA
}

\begin{abstract}
I am aware of the red and orange autumn leaves. Am I aware of my awareness of the leaves? Not so according to many philosophers. By contrast, many meditative traditions report an experience of awareness itself. I argue that such a pure awareness experience must have a non-sensory phenomenal character. I use Douglas Harding's first-person experiments for assisting in recognising pure awareness. In particular, I investigate the gap where one cannot see one's head. This is not a mere gap because I seem to be looking from here. Critically, I claim, the experience of looking from here has a nonsensory phenomenal character. I argue that this sense of being aware cannot be reduced to egocentric visual-spatial relations nor the viewpoint because it continues when I close my eyes. Neither is a multisensory origin sufficient to explain why I seem to be at this central point rather than elsewhere. Traditionally, claims of a pure awareness experience have been restricted to highly trained individuals in very restricted circumstances. The innovation of Harding's approach is that it reliably isolates a candidate for pure awareness using methods which can be replicated at any time.
\end{abstract}

ARTICLE HISTORY Received 25 July 2018; Accepted 4 January 2019

KEYWORDS Buddhism; Douglas Harding; first-person methods; pure awareness; mysticism

\section{Introduction}

I see the red and orange leaves of autumn and hear birds singing. I am aware of objects in the world. But am I aware of my awareness of these things? It seems that my awareness is elusive. I look for it, but can only find objects and their properties. While I know that I see an ant, according to Dretske, 'I don't see myself see an ant' (Dretske 2003, 8). Many philosophers have denied that awareness can be experientially distinguished from the objects of awareness. ${ }^{1}$ James (1904) held that experience 'has

CONTACT Brentyn J. Ramm brentynramm@gmail.com E School of Philosophy, The Australian National University, HC Coombs, Canberra, ACT 0200, Australia; Department of Philosophy, The Ohio State University, 350 University Hall, 230 N Oval Mall, Columbus, OH 43210, USA

${ }^{1}$ Here the term 'object' is used in a wide sense to include not just perceived objects, but also feelings, thoughts, pains and mental images.

(c) 2019 Informa UK Limited, trading as Taylor \& Francis Group 
no such inner duplicity' $(480) .^{2}$ Evans $(1970,53-55)$ denied that there a discernible common property shared by all experiences. Dainton (2002) could find no such 'gaze of consciousness'. These observations are closely related to the transparency (or diaphanousness) of experience, the purported phenomenological fact that when I try to introspect the qualities of my experiences, I am only aware of properties of objects, such as the qualities of a leaf. The greenness is a property of the object, not apparently a quality of consciousness. I can attend to a green thing, but not to a green experience. That is, metaphorically speaking, when I look for my experiences, I 'see through' them to objects in the world (Tye 2002, 139). Experience, therefore, is 'transparent' (Campbell in Campbell and Cassam 2014; Dretske 1995; Harman 1990; Martin 2002; Shoemaker 1996; Tye 1995, 2002, 2014. For doubts about transparency, see Block 1996; Kind 2003; Pace 2007; Siewert 2004).

By contrast, philosophers influenced by meditative traditions hold that awareness itself also contributes to the experiencing of the leaves (Albahari 2009; Deikman 1996; Fasching 2008; Gupta 1998; Shear 1998). A common experience in meditation is that of watching thoughts, feelings and sounds arising and disappearing, while awareness itself seems to remain unchanged. There is a polarity within experience between the objects of awareness and awareness itself (Deikman 1996; Fasching 2008). This aspect has been referred to as 'Witness Consciousness' (Albahari 2009; Gupta 1998; Fasching 2011). Hence the phenomenology of seeing leaves is not exhausted by the shape and colours of the leaves. Awareness itself makes a unique and continuous phenomenal difference over and above sensory qualities. This experiencing of awareness itself, I will refer to as a 'pure awareness experience'. A pure awareness experience is referred to in meditative traditions from diverse cultures. Prominent examples are the Advaita Vedanta (Gupta 1998), Yogācāra Buddhism (Lusthaus 2014), Tibetan Buddhism (Fremantle 2001) and mystical traditions (Forman 1990, 1999; Shear 1998).

If awareness has its own phenomenal character, it seems to be particularly difficult to grasp. G. E. Moore seems to refer to the elusiveness of awareness when in a famous passage he states:

\footnotetext{
${ }^{2}$ James complains that with Kant and the neo-Kantians 'the spiritual principle attenuates itself to a thoroughly ghostly condition, being only a name for the fact that the 'content' of experience is known. It loses personal form and activity - these passing over to the content - and becomes a bare Bewusstheit (awareness) or Bewusstein uberhaupt (consciousness in general), of which in its own right absolutely nothing can be said. I believe that 'consciousness,' once it has evaporated to this state of pure diaphaneity, is on the point of disappearing altogether. It is the name of a nonentity, and has no right to a place among first principles' (James 1904, 477). (Bracketed terms added).
} 
Though philosophers have recognised that something distinct is meant by consciousness, they have never yet had a clear conception of what that something is. They have not been able to hold it and blue before their minds and to compare them, in the same way in which they can compare blue and green. And this for the reason I gave above: namely that the moment we try to fix our attention upon consciousness and to see what, distinctly, it is, it seems to vanish: it seems as if we had before us a mere emptiness. When we try to introspect the sensation of blue, all we can see is the blue: the other element is as if it were diaphanous. Yet it can be distinguished if we look attentively enough, and if we know that there is something to look for. (Moore 1903, 450)

Moore further says that consciousness is the 'common element' between all sensations (450) and explicitly uses the term 'awareness' interchangeably with 'consciousness'. According to Moore then, awareness is elusive, yet experienceable. Moore (1903) is often credited as the historical origin of the transparency of experience, yet this passage suggests that he thought experiencing awareness itself was in fact possible. ${ }^{3}$ If awareness makes a phenomenal difference in addition to the character of its objects (or sensory qualities) this would provide evidence against awareness being exhausted by sensory qualitative phenomenal properties.

Moore says that one can experience their awareness if they 'look attentively enough'. But how exactly? In this regard, the philosopher Douglas Harding has much to offer. Harding developed an unconventional method of self-inquiry which has so far received little attention from other philosophers (though see: Blackmore 2011, 63-65; Fasching 2008; Harris 2014, 141-148; Ramm, 2017). ${ }^{4}$ In particular, Harding provided systematic practical instructions - first-person experiments - for carrying out Moore's advice. I will guide the reader through some of these experiments, the goal being to experience awareness for one's self. There is a seemingly irreconcilable disagreement between philosophers over whether one can experience awareness itself, over and above sensory phenomenal qualities, emotions, etc. If first-person methods could reliably isolate a candidate for pure awareness, this would be a significant result in advancing our understanding of consciousness.

\footnotetext{
${ }^{3} \mathrm{~A}$ common reading of Moore in this passage is that he is talking about qualia (phenomenal properties) as being diaphanous: Block (1996, 26-27), Kind (2003, 229), Tye (1992, 160), Tye (2002, 139), Kennedy $(2009,574-577)$, Speaks $(2009,539)$, Stoljar $(2004,341)$. In fact, in the context of Moore referring to 'consciousness' as the 'common element' to all sensations it is clear that he is referring to awareness as diaphanous (yet distinguishable): see, Albahari (2009, 62-63, 70, 76-77, 83), Fasching (2008, 465), Forman (1999, 112); Metzinger (2003, section 3.2.7).

${ }^{4}$ Harding's book, On Having No Head first published in 1961 and updated in 1986 (Harding 1961), is regarded as a spiritual classic. Excerpts appear in Hofstadter and Dennett (1981).
} 
This first-person inquiry also has consequences for attempts to explain consciousness. The focus on solving the hard problem of consciousness (Chalmers 1995) has been on explaining experiences such as what it is like to see magenta, feel anger, and think about Pi. Explaining these aspects of consciousness arguably leaves untouched the awareness that many claim is common to all experiences. From the perspective of meditative traditions and those influenced by these traditions, the view that consciousness is exhausted by sensory, affective, and cognitive character is an impoverished notion of consciousness. If correct, we could conceivably explain these properties of consciousness, but leave unexplained awareness itself, arguably the essence of consciousness (see Albahari 2009).

The plan for the paper is as follows: I characterise 'pure awareness' in Section 2. In Section 3, I employ first-person experiments from Douglas Harding for recognising pure awareness. In Section 4, I argue that the viewpoint does not explain the phenomenology of pure awareness. I make some concluding remarks in Section 5.

\section{Pure awareness}

\subsection{Characterising the pure awareness experience}

An aspect of the experience of pure awareness which I will focus on in this paper is the claim that it is non-sensory in character. In the words of 'The Tibetan Book of the Dead':

This brilliant emptiness is the radiant essence of your own awareness. It is beyond substance, beyond characteristics, beyond colour... The instant of your own presence is empty, yet it is not a nihilistic emptiness, but unimpeded radiance, brilliant and vibrant ... Your own awareness, a vast luminous expanse, clarity inseparable from emptiness, is also the Buddha of unchanging light, beyond birth and death. Just to perceive this is enough. If you recognize this brilliant essence of your own awareness as Buddha Nature, then gazing into it is to abide in the state of enlightenment. (Padmasambhava and Lingpa 2013, 14-15)

To be empty is to lack inherent self-existence. Pure awareness is empty, but not a mere emptiness (non-existence) because it is luminous. Radiance or luminosity is the 'illuminating potential of the mind' (Fremantle 2001, 199). It is described as pure and transparent and often used interchangeably with 'clear light'. This awareness is colourless and shapeless. It is empty and clear but is nevertheless able to be experienced. The realisation of luminosity is the experience of naked awareness or Buddha Nature 
(Fremantle 2001, 232). Of course, terms such as 'luminous' and 'radiant' are intriguing, but in the end are just visual metaphorical terms to refer to awareness. ${ }^{5}$ Alternatively, to the term 'awareness', the phenomenon could be referred to as the 'knowing aspect' of experiencing, as distinct from the objects known (Albahari 2006, 8; Thompson 2014, xxi).

Whilst inspired by traditional sources, the following characterisation of pure awareness is predominately based upon philosophical and phenomenological considerations, rather than an exegesis of traditional texts. I will understand 'pure awareness' by the following set of characteristics:

(1) It is the common element to all experiencing.

(2) It lacks sensory and affective phenomenal qualities normally associated with consciousness such as colour, shape, sound, taste, emotional qualities, and so forth.

(3) It has a sui generis non-sensory, non-affective phenomenal character.

(4) It is non-cognitive.

(5) It is experienced non-objectifyingly.

I elaborate on these characteristics below:

(1) It is the common element to all experiencing.

As Moore (1903) states it:

We all know that the sensation of blue differs from that of green. But it is plain that if both are sensations they also have some point in common. What is it that they have in common? And how is this common element related to the points in which they differ? I will call the common element 'consciousness' without yet attempting to say what the thing I so call is. We have then in every sensation two distinct terms, (1) 'consciousness,' in respect of which all sensations are alike; and (2) something else, in respect of which one sensation differs from another. It will be convenient if I may be allowed to call this second term the 'object' of a sensation: this also without yet attempting to say what I mean by the word. (Moore 1903, 450)

This awareness is common to all sensory modalities. Albahari (2009) refers to it as a 'mode-neutral awareness'. A reason for thinking that modeneutral awareness exists is the unity of consciousness. ${ }^{6}$ Take the

\footnotetext{
${ }^{5}$ For detailed overviews of the concept of luminosity as it has been used in Buddhist traditions see Mackenzie (2017) and Skorupski (2012).

${ }^{6}$ Providing a definition of the unity of consciousness would go beyond the scope of this paper. See, Bayne (2010), Bayne and Chalmers (2003), Brook and Raymont (2014), Cleeremans (2003), Dainton (2000) and Tye (2003).
} 
experience of gardening as an example. I am aware of the plants and their colours and shapes, the smell of the soil and the warmth of the sun. I am aware of all of these things simultaneously. There is a unified experience. This suggests that there is an awareness which encompasses all of these sensory modalities, and is hence neutral between modalities. I add that it also has to be intra-mode neutral (e.g. neutral between colours, as well as neutral between visual and auditory phenomenology) so that I can be simultaneously aware of all the sensory properties within a modality (e.g. the multi-coloured garden scene).

(2) It lacks sensory and affective phenomenal qualities normally associated with consciousness such as colour, shape, sound, taste, emotional qualities and so forth.

Why think that awareness is pure in the sense of lacking sensory phenomenal qualities in itself? If awareness had any sensory or affective phenomenal qualities whatsoever, then it would be incompatible with being the common aspect to all experiences. If awareness was red for instance, it would be like looking through red cellophane such that all blue things would appear purple. If awareness is the common element in blue, red, green, yellow etc. experiences, then it cannot be blue, red, green, or yellow, rather it must be colourless. If awareness is common to all shape sensations, it cannot be square, circular, triangular, etc. but must be shapeless. To be compatible with all colours, shapes, sounds, etc. then awareness must, in itself, be colourless, shapeless, silent, etc. As Shear and Jevning (1999) point out, only a consciousness that is devoid of sensory qualities could possess 'omni-compatibility' with all sensory phenomena.

(3) It has a sui generis non-sensory, non-affective phenomenal character.

Pure awareness should be distinguished from a bare awareness which has no phenomenal character at all. To be experienceable pure awareness must make a phenomenal difference, that is, it must have its own unique non-sensory, non-affective phenomenal character. Otherwise phenomenologically speaking such an awareness would not exist (Albahari 2009; Dainton 2002; Thompson 2015, 19). As Dainton (2002, 45-46) points out, phenomenal character need not be restricted to sensory qualities such as tastes, sounds and colours: 
A consciousness which consists of nothing but a feeling of void-like emptiness has a definite (if difficult to describe) phenomenal character. An 'awareness' of this kind is tangible rather than pure, even if it is natural to describe it as 'pure'. By contrast, a truly bare awareness has absolutely no phenomenal character of any kind, and so is subjectively indistinguishable from non-existence.

I will continue to use the term 'pure' here as 'pure awareness' is one of the standard terms for this form of awareness, though it should be kept in mind that by this I mean what Dainton calls 'tangible awareness'.

(4) It is non-cognitive.

Cognitive phenomenology is the conscious experience of thinking that $\mathrm{P}$, desiring that $\mathrm{P}$, intending that $\mathrm{P}$, etc. which is held to have a non-sensory phenomenal character (Horgan and Tienson 2002; Pitt 2004; Siewert 1998; Strawson 1994). Pure awareness, however, is non-cognitive. It is present with all conscious episodes including when there are no conscious thoughts. There are frequently at least brief moments such as when I am looking at a sunset in which I am not thinking at all, but I am nevertheless still seem to be aware.

(5) It is experienced non-objectifyingly.

Though awareness is known by direct experience it is not experienced as an object of awareness; Rather awareness is experienced non-objectifyingly. As an example, Sartre states 'consciousness of consciousness except in the case of reflective consciousness ... is not positional, which is to say that consciousness is not for itself its own object' (Sartre 1957, 40-41). As Fasching states it, 'by just observing, one experiences oneself non-observationally as the observing itself, as 'pure seeing' (Fasching 2008, 470).

According to Buddhist thinkers Dignāga, Dharmakirti, and Santaraksita, awareness has an inbuilt self-awareness - it is 'self-luminous' (Mackenzie 2007). It illuminates itself at the same time as illuminating its objects. There is no higher-order awareness directed at awareness, which takes awareness as its own object. This view is also found in the Upanishads (Gupta 1998). This is a reflexive, or first-order, notion of awareness of awareness. A similar position is also widely held by phenomenologists such as Husserl, Sartre, Gurwitsch and Merleau-Ponty (Gallagher and Zahavi 2010; Zahavi 2005) and also by a number of contemporary 
philosophers (Albahari 2009; Deikman 1996; Kriegel 2003, 2009; Montague 2016; Nida-Rümelin 2014; Strawson 2011, 2015; Zahavi and Kriegel 2015).

I am also inclined to say that awareness is intrinsically self-aware (and hence self-aware at all times). However, the phenomenology investigated in this paper is also compatible with an alternative view in which the sense of being aware comes and goes, rather than being present with all episodes of experiencing. Consider, for example, states of absorption in an object of experience. This state may well involve a loss of all sense of being aware. Awareness would always be present, but it would sometimes (or perhaps frequently) be unaware of itself. The important point for present purposes is that awareness is at least sometimes experienceable and that it is not experienced as an object of awareness.

I will be focused on isolating a non-sensory phenomenal character of pure awareness using the visual modality. I will hence be setting aside the non-auditory, non-tactile, non-affective (and so forth) character of pure awareness. It should be emphasised that the goal is to experience awareness via the visual modality, rather than 'in' the visual modality. The idea here is that a mode-neutral awareness can be experienced by using the visual modality, but awareness is not itself in any sensory modality. Rather awareness encompasses all sensory modalities. Another common gateway to experiencing pure awareness is via the auditory modality, in particular, it is often described as a 'silent awareness' underlying heard sounds (e.g. Forman 1998, 193-194).

\subsection{Two types of pure awareness experience}

It has been claimed by many that pure awareness can be recognised in a deep meditative state - a Pure Awareness Experience (or event) (PAE). This has been characterised as 'a wakeful though contentless (nonintentional) consciousness' Forman (1990, 8), and as possessing 'no phenomenal content at all, no colours, sounds, thoughts, anticipations, etc ... In short, the experience is simply awareness itself' (Shear and Jevning 1999, 195). As there are no objects of experience it is a state in which there is no subject-object duality. According to Yogic, Advaita Vedanta, and Tibetan Buddhist traditions, objectless pure awareness is also naturally experienced in dreamless sleep (Thompson 2014). Recently, Thompson (2014, 2015), Windt (2015), and Windt, Nielsen, and Thompson (2016) argue that sleep studies of subjects reporting being aware during dreamless

\footnotetext{
${ }^{7}$ Contrary to what I said elsewhere (Ramm, 2017, 148). Thanks to Miri Albahari for making this point to me.
} 
sleep provide evidence for these traditional accounts of objectless pure awareness experience.

I understand such experiences to mean a conscious state in which there is awareness of awareness but no objects of awareness. I assume that nevertheless a PAE has a unique phenomenal character even if there are no objects of awareness, and no sensory phenomenal character. While Shear and Jevning (1999) do say that it has 'no phenomenal content' (195), I read them as saying that it does not have sensory qualities, rather than having no phenomenal character at all, otherwise it could not be categorised as being an experience. In any case, this is how I will understand this type of experience. Let us call this an Objectless Pure Awareness Experience. This can be distinguished from an Object-Directed Pure Awareness Experience. In the latter, there is an experience of an awareness which has a non-sensory phenomenal character (pure awareness), simultaneously with there being objects of awareness and sensory phenomenal properties. In fact, most (if not all) experiences will have objects of awareness and sensory phenomenal properties however vague and hence sensory phenomenal character. This is my experience, though I am not an advanced meditator. I remain neutral as to whether or not there can be a truly Objectless PAE. The aim of this paper is to find an Object-Directed PAE rather than an Objectless PAE. ${ }^{8}$

\section{First-person methods}

In this section, I use first-person experiments developed by Douglas Harding as a means for distinguishing awareness, in particular pure awareness, from the objects of awareness. These experiments are conducted using the visual modality, and hence the focus is on isolating pure awareness visually. ${ }^{9}$

The first-person experiments used here consist of three main components: The first component is going by how things seem rather than

\footnotetext{
${ }^{8}$ Stace (1961) makes a similar distinction between 'introvertive' and 'extrovertive' mystical experiences. 'The extrovertive experience looks outward through the senses, while the introvertive looks inward into the mind' (61). The latter involves 'a state of pure consciousness - "pure" in the sense that it is not the consciousness of any empirical content. It has no content except itself' (86). Shear (1998) eludes to the Object-Directed PAE where he says 'after one's attention has been drawn frequently to pure consciousness in meditation (with all other objects of awareness absent), it should become possible to recognize it at will afterward, even when the other ordinary components of experience have returned to one's awareness ... as meditation traditions often report' (681). Forman (1999) refers to the 'dualistic mystical experience' as an inner silence that is experienced 'concurrently with changing external experiences, including thinking and feeling' (150) (see also Forman 1998, 193-197).

${ }^{9}$ Experiment 1 is from Harding. Experiments 2, 3, and 4 are my own variants on his experimental method.
} 
how you believe them to be. For example, in viewing the Müller-Lyer illusion, I would judge that the lines look different in length, even though I believe that they are actually equal in length. In particular, this method involves setting aside the third-person perspective and simply taking your experience exactly as it is given. The second component is distinguishing by phenomenal contrast (Siegel 2007). Here two phenomena are compared so as to make salient the phenomenal difference between them. Thirdly, unlike standard forms of 'introspection' these methods use apparatus such as a pointing finger to make the phenomenal contrast and to assist in orienting attention to the target phenomenon. In particular, the aim of the following first-person experiments is to provide systematic methods, via the manipulation of attention, of contrasting awareness with the objects of awareness exactly as Moore suggests we need to. ${ }^{10}$

\subsection{Experiment 1: the pointing experiment}

Please do the following. Use your finger to point at a wall. Notice that you are pointing at a thing with colour, shape and texture. Point at the floor and notice its various colours and textures. Now point at your foot and then slowly trace your pointing finger up your body noticing its threedimensional volume, and various colours and textures of your limbs and clothes. Finally turn your finger around so that it is pointing where others see your face. On present experience do you seem to be pointing at a face? Are there any colours here? Shapes? Textures? Movement? Any personally identifying attributes such as name, gender, race, or species? I find that these characteristics are all missing from this spot. Rather this is apparently just a gap, or open space. ${ }^{11}$ Recall, that lack of colour, shape etc. is exactly what was predicted to be a defining characteristic (or lack of characteristic) of awareness, so we have found a plausible candidate for pure awareness. ${ }^{12}$

\subsection{Experiment 2: finding awareness}

Where are you looking from? Hold up your hand in front of you. Are you looking from the left of the hand? The right of the hand? Or is the place

\footnotetext{
${ }^{10}$ For a defence of first-person experiments, see Ramm (2018).

${ }^{11}$ By 'space' I do not mean the space of physics, but rather I use it as a descriptive term in the sense of a gap or opening, and also in terms of it seemingly functioning as room or capacity (in a container sense) for the scene.

${ }^{12}$ For examples of the pointing experiment see: Harding (1961, 42-43, 1990, 8-9, 41-42; 2000, 8-9), Lang (2003, 6-7).
} 
you are looking from located at 180 degrees from the hand? I find the latter. I am aware from here. To further test this try pointing outwards at various objects. I find that I point at objects such as a table, a chair, and a wall. I see things and surfaces that are composed of shapes and colours, but at no time do I actually point at my awareness. Certainly, I am aware of the objects, but I am pointing at the objects not my awareness of the objects. There is no awareness out there on present evidence. By a process of elimination the only place left to look for my awareness is right here, by turning the arrow of my attention around 180 degrees. Another means of phrasing the question is: in which direction do I find myself as looker? In my experience, it is only by pointing inwards, and not outwards, that I am pointing at the looker, and all I mean here by looker is 'that which is visually conscious'. I am visually aware from here, not from any other direction. ${ }^{13}$

\subsection{A visual blind spot?}

One response to the experiments is to hold that $\mathrm{I}$, in fact, experience nothing in this direction. It is merely a visual blind spot. Eyes cannot look backwards, and so there is no information to receive from this location, and so, of course, I see nothing here. It is merely a visual absence. The problem with my above descriptions according to the objection is that it confuses a complete lack of visual experience, with an experience that lacks visual sensory properties. As Daniel Dennett puts it, 'an absence of information is not the same as information about an absence' (Dennett 1991, 324). Perhaps then it should be described as a bare lack of visual experience, a pure visual absence.

A pure visual absence can be contrasted with a blind spot that has experiential contents. For example, when my foot is occluded by the table, I see the table but not my foot. The experience is of the table (not nothing). This is a blind spot by occlusion. Another type of blind spot is a blind spot by vacancy. Examples of these blind spots are holes and gaps. For example, when I look at a gap formed by a doorway there is a character of emptiness to the experience. A pure blind spot, or pure visual absence, on the other hand has no phenomenal character whatsoever. It is a

\footnotetext{
${ }^{13} \mathrm{I}$ use the terms 'looking' and 'visually aware' interchangeably. A different sense of 'looking' is one in which I am actively attending. Active visual attention has its own phenomenal character such as the sense of effort in controlling one's attention. Metzinger (2017) posits a model of mental agency (including controlled attention and deliberate thinking) which contributes to a phenomenal self-model. This is a different phenomenology from what I mean by 'looking' and 'visually aware'. There is a sense of being visually aware even when one is not actively controlling visual attention, or so I claim.
} 
complete absence of experience. We investigate this alternative further in the next experiment.

\subsection{Experiment 3: pure blind spot and blind spot by vacancy}

(1) Pure blind spot: Look directly ahead and move your hand slowly to the left. Notice that your hand begins to blur and eventually disappears altogether. You have found the limit of your visual field. Notice that unlike the boundaries of things there is nothing outside of it. For example, I see the edges of the table because it is in a surrounding environment such as the room. But 'outside' of my visual field, I can see nothing whatsoever. Beyond the limits of the visual field, I find a true blind spot, a pure visual absence. The visual scene just ends. (2) Blind spot by vacancy. If I merely experience nothing where I am looking from, if it is a pure blind spot like beyond the limits of my visual field, then what it is like to attend here should be exactly the same as there. Point off to the side and attend to that spot. I am pointing at nothing whatsoever, no things, no colours, no shapes, and there is nothing it is like to experience that location. It is a bare lack of visual experience. Now by contrast point at where you are looking from. There is a phenomenal difference between the two spots. I am again pointing at no things, colours, or shapes, but there is something it is like to attend here. Rather than no experience at all, there is a phenomenal character of spacious emptiness. This is a more like a blind spot by vacancy than a pure blind spot. I experience this location like I do a hole, not the same as the complete lack of phenomenal character when I try to attend to what is beyond my visual field.

\subsection{Experiment 4: blind spots and the aware spot}

I experience this location like a gap, but is it merely a gap? The question of this experiment is where seems to be the location of the looker. (1) Blind spot by vacancy: Point to the gap formed by an open doorway. In a sense you are pointing at nothing. I seem to be pointing at no shapes or colours and not at the looker. (2) Aware Spot. Now point towards where others see your face. There is a phenomenal difference between the gap of the doorway and this spot. Again, there are no shapes and colours, but I am also seemingly pointing at the looker, or the locus of visual awareness. While pointing here Douglas Harding asks us to notice: 
Whether what I'm pointing at is face-like or space-like, human or non-human, a thing or nothing, small and bounded or limitless, dead to itself or alive - alive to Itself, in all Its blazing obviousness and uniqueness. (Harding 1992, 27)

A gap in a doorway has a spacious emptiness to it simpliciter. By contrast, this spot is awake to the finger and the room. This is seemingly a spacious emptiness that is aware. Rather than being a mere blind spot, this is apparently an aware-spot, in fact, it is the only aware-spot I can find. Critically, there is a phenomenal difference between the two types of vacancy, and this experience of awareness is non-sensory in character.

\subsection{Interpreting the results of the experiments}

I am self-evidently aware. I had assumed with common sense that I am looking out of a thing - out of two eyes in a solid, opaque ball. That is, I had assumed that I am a person that is aware. However, when I attend in this direction - when I attend to who or what is looking there is no person. There are apparently no eyes, nor cheeks, nor hair here, neither are there shapes or colours. I seem to be attending to an open space, not a thing. Taking my experience as I find it, it is a no-thing that is aware, rather than a thing. ${ }^{14}$ Rather than nothing, or a pure lack of experience, this can be described as an awarespace (Harding 1996, 83; Harding 1988, 135), or aware-capacity (Harding 1992, 28).

Importantly, there is a non-sensory phenomenal difference between this spot and a mere gap - that it seems to be aware. Neither is this sense of awareness an object of awareness. I am not aware of it as objects of awareness such as trees, houses, my body, feelings or thoughts. I am aware of these things, while I am apparently aware as this space. The target arguably fits the characteristics of what we were searching for, namely, pure awareness.

\section{Spatial visual structure and the viewpoint}

One may suspect that the experiments rely upon the spatial structure of vision, that is, visual space as experienced from a first-person point of view. Examples include left, right, in front. There is also the central point in vision, the viewpoint. The visible side of things apparently face this

\footnotetext{
${ }^{14}$ Thanks to Robert Penny for highlighting these important points to me. See Richard Lang on the observation that I am self-evidently aware (Lang 2003, 8).
} 
centre in egocentric space. ${ }^{15}$ Non-Egocentric space, on the other hand, has coordinates that are not relative to a point of view, such as north, west and south. This type of space has no viewpoint or centre which things face. Campbell $(1994,119)$ distinguishes between monadic and relational egocentric information. ' $X$ is to the left' is an example of a monadic egocentric property. ${ }^{16}$ ' $X$ is to the left of $m e^{\prime}$ is an example of an egocentric relation. He holds that the visual information does not have an inbuilt reference to the subject but rather is monadic. However, a relational description can also exclude a specific reference to a subject. ${ }^{17}$ Things are seen as located to the left of centre and right of centre, and at a distance from here. Perhaps then it is just built into visual experience that things are at a distance from here, and this explains the sense of awareness or the looker being here. The advantage of this proposal is that it would provide an invariant structure to visual experience to account for the phenomenology. Do I seem to be pointing at the looker because I am pointing at the viewpoint?

If the experience is reducible to the spatial aspects of the visual field such as the viewpoint then closing my eyes should eliminate the sense that I am looking from here and hence the sense of being aware. The final experiment is from Deikman (1996) who uses a method of contrast for distinguishing awareness.

\subsection{Experiment 5: eyes closed experiment}

Look straight ahead. Now shut your eyes. The rich visual world has disappeared to be replaced by an amorphous field of blackness, perhaps with red and yellow tinges. But awareness hasn't changed. You will notice that awareness continues as your thoughts come and go, as memories arise and replace each other, as desires emerge and fantasies develop, change and vanish. (Deikman 1996, 351)

When I close my eyes my experience of awareness does not change. When the lights go out, if anything, the experienced polarity between the observing aspect and the observed (the blackness) is even more salient. This is the case even though there is no three-dimensional spatial information and arguably no viewpoint. For example, a photo of a street scene has a viewpoint which things face and recede into the distance

\footnotetext{
${ }^{15}$ For further discussion on egocentric information see Peacocke (1992, chapter 3 ) on scenarios, and Bermúdez (1998, chapter 5) on self-specifying information in vision.

${ }^{16}$ Colours are another example of monadic visual properties.

${ }^{17}$ Casullo $(1986,1989)$ argues that objects have their positions in perceptual space in virtue of monadic position properties, while Falkenstein (1989) argues in favour of relations.
} 
from. However, a photo of a totally dark room represents nothing but blackness - it does not represent a viewpoint. If it does depict a viewpoint it is only in a very abstract sense of the term, like a centre of gravity. This suggests that there is also no viewpoint when I close my eyes.

Perhaps the dots or the even blackness are experienced as being some distance away? This is worth considering, though it is far from clear to me. Even if there is sometimes a sense of distance, much of the time there is just blackness with no depth at all. If this is correct, it shows that the sense that the looker is here is not reducible to the visual viewpoint.

Perhaps there is other spatial information that can explain the invariant aspect when one closes one's eyes. For example, there are other central points in egocentric space such as in the proprioceptive field and the auditory field. This proposal raises a number of puzzles. The central points in vision and proprioception are different, at least it is not clear that the centre of proprioceptive experience coincides with the head. This raises the question of which centre I seem to be located at. I do not seem to suddenly shift centre when I close my eyes. It is not even clear that there is a single central point in proprioceptive experience. Perhaps, the centre of the auditory field is approximately where the head is apparently located, but what about when everything is completely silent? Does the sense of awareness disappear in a totally dark and silent room? These sources of information seem to be too variable to explain the invariance of the observing aspect.

These objections can be avoided by positing a multi-modal central point. This central point would not depend upon any one sense, but would rather serve as the central point of all the senses. Blanke and Metzinger $(2009,8)$ describe this as:

A purely geometrical feature of a perceptual or imagined model of reality possessing a point of projection functioning as its origin in sensory and mental processing, but is not linked with theoretically more charged notions such as 'subject of experience'. (Blanke and Metzinger 2009) ${ }^{18}$

However, this proposal suffers from a more pressing problem which also applies to the viewpoint. The critical question is: Why I should seem to be looking from here rather than somewhere else? I honestly do not know. Why should I seem, as the looker, to be at this central point rather than at a peripheral point? This is entirely mysterious. Locating a central point is not the same as me seeming to look from that point.

\footnotetext{
${ }^{18}$ See Dainton (2016) for a similar proposal.
} 
What explains the phenomenal difference between a mere gap in a doorway and my apparently looking from the gap where others see my face? It seems that we need an extra phenomenal ingredient. If this is correct then there is more to the phenomenology than just a central point. Something further it seems is required to fix 'the observer' at a central sensory point. We are back then to the invariant sense of being aware that we set out to explain in the first place.

Another way in which phenomenology goes beyond the viewpoint is its character of spacious emptiness. This apparently empty region from which I seem to be looking is not experienced as a mere point but as an unbounded opening. It would be better not to say that I find a viewpoint where I am looking from, but a view-space. Unlike a mere point which cannot contain anything, this transparent opening encompasses the visual scene. This seemingly blank region also remains distinguishable from the darkness when I close my eyes. Schwitzgebel (2011) asked subjects to introspect what it was like with their eyes closed. He inquired

if it seemed to them that they experienced blackness or grayness or anything else visual in the region behind their heads and beyond the farthest boundary of their peripheral vision, or whether it seemed instead empty or blank - not black, but rather entirely devoid of visual experience. All expressed the view that beyond the visual periphery it was visually blank, not black. (Schwitzgebel 2011, 152-153)

I would say from my experience that I seem to be this blank space which encompasses the darkness. When I close my eyes, the contents of this aware-space change from a multi-coloured scene to darkness, but the space itself remains unchanged.

\section{Conclusion}

Moore held that philosophers have not recognised the centrality of awareness to the problem of consciousness because 'they have not been able to hold it and blue before their minds and to compare them, in the same way in which they can compare blue and green' (Moore 1903, 450). I presented a series of first-person experiments developed by Douglas Harding for experiencing awareness by contrasting it with objects of awareness. I found that the sense that I am looking from here (where others see my face), fits the characteristics of pure awareness in that it has a nonsensory phenomenal character and is not experienced as an object of awareness; in particular, this gap fits the description of a 'luminous emptiness'. 
If the descriptions provided here are correct then when Moore uses the terms 'transparent', and 'emptiness' in regards to awareness, these turn out to be more than metaphorical flourishes, but actually describe a distinguishable aspect of the structure of experience. Sartre's $(1957,40)$ view on consciousness was also close to that of pure awareness stating that 'All is ... clear and lucid in consciousness: the object with its characteristic opacity is before consciousness, but consciousness is purely and simply consciousness of being consciousness of that object'. Awareness is clear, and it is because of its perfect clarity that its contribution to phenomenal life tends not to be recognised.

That awareness is experientially distinguishable from objects of awareness is not to posit that there is a metaphysical duality between awareness and objects of awareness. For Buddhist thinkers such as Dignāga, awareness and objects of awareness are aspects of a single unity, and hence they are not separable (Hattori 1968; Ho 2007, 216). Harding holds that because awareness is in total contrast to the things it's aware of, they are absolutely united. 'Paradoxically,' Harding states, 'just because this Space is absolutely unlike and absolutely uncontaminated by its contents, it is absolutely identified with them. I don't believe this, I see it. The Space is the things that occupy it. This Stillness-Silence is the motions and the sounds of which it is the background' (Harding 1961, 60).

Consider how this gap and the objects it encompasses differ from relative opposites such as black and white. A thing cannot be both entirely black and entirely white simultaneously. Black and white cannot be present at the same location except by mixing to create grey. Black and white are incompatible because they are both colours on the colour continuum. ${ }^{19}$ However, this aware-gap is compatible with objects because they are absolute opposites. There are no colours or shapes here to conflict with the colours and shapes of objects, and thus they are perfectly unified. ${ }^{20}$ On a practical note, Harding $(1967,1986,1990,2000)$ highlights the potential benefits of a conscious 'headlessness' for my being open to others. In my first-person experience I am never face-to-face with others, but rather face-to-no-face. Nothing gets in the way between myself and

\footnotetext{
${ }^{19}$ Technically speaking, according to physics, black and white are not colours at all. Black is an absence of reflected light, and white is a mixture of red, green, and blue light. I am using 'colour' here in the way it is employed in ordinary languages such that 'black' and 'white' count as basic categories of colour (Berlin and Kay 1969).

${ }^{20}$ This type of non-duality by absolute unity is distinct from non-duality by extinction of the object as reportedly occurs for objectless pure awareness experiences. It is also distinct from non-duality by extinction of awareness (or the subject), such as in states of absorption in the object. An in-depth analysis of non-duality goes beyond the scope of the present paper.
} 
the other's face. I don't confront them - I am replaced by them (Harding $1967,48)$.

This aware spot was also found to be impersonal in that it seemingly lacks all personally identifying characteristics such as gender, personality, social identity etc. To be more precise we should call this a 'zero-person experience'. ${ }^{21}$ The delusion I usually live from is that there is a person or observing thing (Harding 2001, 15) (who is the subject) residing at the centre of my phenomenal world. I propose rather that the subject is awareness itself, and it is egoless and impersonal (Albahari 2006, 2009; Deikman 1996; Forman 1999; Harding 1988, 110, 2000, 102; Shear 1998). Egos and persons are objects of awareness, not the subject. Neither is this awaregap bounded by anything (I experience nothing outside of it). This gap is not separate from the visual scene. There is apparently no dividing line, between it and the scene. They are seemingly totally unified. If by 'self' then we mean an ontologically separate thing with personally identifying characteristics, and if we take phenomenology as a guide to metaphysics, then as a boundless, non-separate, and impersonal non-thing, this aware-space is selfless. ${ }^{22}$

The experiments presented here assist in isolating a phenomenal difference, however they do not dictate which language should be used to describe it. For the conscientious sceptic the present methods provide a means for further investigation. Scepticism is an essential part of the scientific attitude. As part of a rigorous first-person approach, scepticism should also be applied to our common-sense beliefs as well, not to mention hallowed philosophical and spiritual beliefs. If, as some claim, awareness is not an object or process in the world, then it is literally unlike any phenomenon so far investigated by third-person science. ${ }^{23}$ Harding $(1992,86)$ on the experience of awareness states: 'The reason I can't tell (you) ... what it's like is that it isn't like anything, that it differs absolutely from everything it's conscious of'. Many meditative traditions hold that pure awareness exists, and where I am apparently looking from seems to be the best 'place' to find it.

Eastern and mystical descriptions of consciousness have typically been discounted on the grounds that they are merely cultural artefacts (Katz 1978), non-verifiable, and too 'esoteric' to enter the realms of

\footnotetext{
${ }^{21}$ For Harding on the first-person as zero, see Harding (2001, 14-15). There is a broader sense of 'firstperson experience' in which is it is that which is had by me, whatever ' $I$ ' turn out to be.

${ }^{22}$ See Albahari $(2006,2011)$ on the distinction between the subject and personal selves. I argue elsewhere that the gap is the subject of experience (Ramm, 2017).

${ }^{23}$ For an argument that first-person science complements and completes third-person science, see Harding (2001).
} 
scientific study. Indeed, a major problem has always been how to study a conscious 'state' that is reported by only a small number of individuals and one that even for them is not always reliably accessible. Rather than being a state that only occurs under very unusual conditions or after years of meditation, Harding's experiments provide results that can be replicated at any time. Even if an agreement on describing the experience is difficult to achieve (not to mention agreement on the metaphysical implications), it is significant progress to identify a candidate for pure awareness and reliable methods for experiencing it. Harding's experiments hence indicate a new avenue of investigation in the science of consciousness.

\section{Acknowledgements}

Thank you to Miri Albahari, David Chalmers, Declan Smithies and Daniel Stoljar for helpful comments on versions of the manuscript. Thank you also to Robert Penny for insightful correspondence about Douglas Harding's views on awareness.

\section{Disclosure statement}

No potential conflict of interest was reported by the author.

\section{References}

Albahari, M. 2006. Analytical Buddhism: The Two-Tiered Illusion of Self. Houndmills: Palgrave MacMillan.

Albahari, M. 2009. "Witness-Consciousness: Its Definition, Appearance and Reality." Journal of Consciousness Studies 16 (1): 62-84.

Albahari, M. 2011. "Nirvana and Ownerless Consciousness." In Self, No Self? Perspectives from Analytical, Phenomenological, and Indian Traditions, edited by M. Siderits, E. Thompson, and D. Zahavi, 79-113. Oxford: Oxford University Press.

Bayne, T. 2010. The Unity of Consciousness. Oxford: Oxford University Press.

Bayne, T., and D. Chalmers. 2003. "What Is the Unity of Consciousness?" In The Unity of Consciousness: Binding, Integration and Dissociation, edited by A. Cleeremans, 23-58. Oxford: Oxford University Press.

Berlin, B., and P. Kay. 1969. Basic Color Terms: Their Universality and Evolution. Berkeley: University of California Press.

Bermúdez, J. L. 1998. The Paradox of Self-Consciousness. Cambridge: The MIT Press.

Blackmore, S. 2011. Zen and the Art of Consciousness. London: One World Publications. Blanke, O., and T. Metzinger. 2009. "Full-body Illusions and Minimal Phenomenal Selfhood." Trends in Cognitive Sciences 13 (1): 7-13.

Block, N. 1996. "Mental Paint and Mental Latex." In Philosophical Issues 7: Perception, edited by E. Villaneuva, 19-49. Atascadero, CA: Ridgeview. 
Brook, A. and P. Raymont. 2014. "The Unity of Consciousness." In The Stanford Encyclopedia of Philosophy, edited by E. N. Zalta. http://plato.stanford.edu/ archives/win2014/entries/consciousness-unity/.

Campbell, J. 1994. Past, Space and Self. Cambridge, MA: The MIT Press.

Campbell, J., and Q. Cassam. 2014. Berkeley's Puzzle: What Experience Teaches Us. Oxford: Oxford University Press.

Casullo, A. 1986. "The Spatial Structure of Perceptual Space." Philosophy and Phenomenological Research 46 (4): 665-671.

Casullo, A. 1989. "Perceptual Space Is Monadic." Philosophy and Phenomenological Research 50 (1): 131-134.

Chalmers, D. J. 1995. "Facing up to the Problem of Consciousness." Journal of Consciousness Studies 2 (3): 200-219.

Cleeremans, A. 2003. The Unity of Consciousness: Binding, Integration and Dissociation. Oxford: Oxford University Press.

Dainton, B. 2000. Stream of Consciousness: Unity and Continuity in Conscious Experience International Library of Philosophy. London: Routledge.

Dainton, B. 2002. "The Gaze of Consciousness." Journal of Consciousness Studies 9 (2): 31-48.

Dainton, B. 2016. "The Sense of Self." Aristotelian Society Supplementary Volume 90: 113-143.

Deikman, A. J. 1996. "I = Awareness." Journal of Consciousness Studies 3 (4): 350-356.

Dennett, D. C. 1991. Consciousness Explained. Boston, MA: Little, Brown and Company.

Dretske, F. 1995. Naturalizing the Mind. Cambridge, MA: The MIT Press.

Dretske, F. 2003. "How Do You Know That You Are not a Zombie?" In Priviledged Access, edited by B. Gertler, 1-13. Aldershot: Ashgate Publishing Limited.

Evans, C. O. 1970. The Subject of Consciousness. London: G. Allen \& Unwin.

Falkenstein, L. 1989. "Is Perceptual Space Monadic?" Philosophy and Phenomenological Research 49 (4): 709-713.

Fasching, W. 2008. "Consciousness, Self-Consciousness, and Meditation." Phenomenology and the Cognitive Sciences 7 (4): 463-483.

Fasching, W. 2011. "I Am the Nature of Seeing: Phenomenological Reflections on the Indian Notion of Witness-Consciousness." In Self, No Self? Perspectives from Analytical, Phenomenological, and Indian Traditions, edited by M. Siderits, E. Thompson and D. Zahavi, 193-216. Oxford: Oxford University Press.

Forman, R. K. 1990. The Problem of Pure Consciousness. Oxford: Oxford University Press.

Forman, R. K. 1998. "What Does Mysticism Have to Teach Us About Consciousness?" Journal of Consciousness Studies 5 (2): 185-201.

Forman, R. K. C. 1999. Mysticism, Mind, Consciousness. Albany, NY: State University of New York Press.

Fremantle, F. 2001. Luminous Emptiness: A Guide to the Tibetan Book of the Dead. Boston, MA: Shambhala Publications.

Gallagher, S. and D. Zahavi. 2010. "Phenomenological Approaches to SelfConsciousness." In The Stanford Encyclopedia of Philosophy, edited by E. N. Zalta. http://plato.stanford.edu/archives/win2010/entries/self-consciousnessphenomenological/.

Gupta, B. 1998. The Disinterested Witness: A Fragment of the Advaita Vedanta Phenomenology. Evanston, IL: Northwestern University Press. 
Harding, D. E. 1961. On Having no Head: Zen and the Rediscovery of the Obvious. Revised ed. London: The Shollond Trust, 2001.

Harding, D. E. 1967. "The Face Game." Transactional Analysis Bulletin 6 (22): 40-52.

Harding, D. E. 1986. "'Confrontation': The Game People Play." Transpersonal Transactional Analysis 16: 99-109.

Harding, D. E. 1988. The Little Book of Life and Death. London: The Shollond Trust, 2001. Harding, D. E. 1990. Head Off Stress. London: The Shollond Trust, 1999.

Harding, D. E. 1992. The Trial of the Man Who Said He Was God. London: The Shollond Trust, 2002.

Harding, D. E.. 1996. Look for Yourself: The Science and Art of Self-Realisation. London: Head Exchange Press.

Harding, D. E. 2000. Face to No-Face: Rediscovering our Original Nature. Carlsbad, CA: InnerDirections Publishing.

Harding, D. E. 2001. The Science of the 1st-Person: It's Principles, Practice and Potential. London: The Shollond Trust.

Harman, G. 1990. "The Intrinsic Quality of Experience." In Philosophical Perspectives 4: Action Theory and Philosophy of Mind, edited by J. Tomberlin, 31-52. Atascadero, CA: Ridgewell Publishing Company.

Harris, S. 2014. Waking Up: A Guide to Spirituality Without Religion. New York: Simon and Schuster.

Hattori, M. 1968. Dignaga, on Perception. Cambridge, MA: Harvard University Press.

Ho, C.-H. 2007. "Consciousness and Self-Awareness." Asian Philosophy. 17 (3): 213-230.

Hofstadter, D. R., and D. C. Dennett. 1981. The Mind's i: Fantasies and Reflections on Self and Soul. New York: Basic Books.

Horgan, T., and J. Tienson. 2002. "The Intentionality of Phenomenology and the Phenomenology of Intentionality." In Philosophy of Mind: Classical and Contemporary Readings, edited by D. J. Chalmers, 520-533. Oxford: Oxford University Press.

James, W. 1904. "Does 'consciousness' Exist? The Journal of Philosophy, Psychology and Scientific Methods 1 (18): 477-491.

Katz, S. T. 1978. "Language, Epistemology, and Mysticism." In Mysticism and Philosophical Analysis, edited by S. T. Katz, 22-74. New York: Oxford University Press.

Kennedy, M. 2009. "Heirs of Nothing: The Implications of Transparency." Philosophy and Phenomenological Research 79 (3): 574-604.

Kind, A. 2003. "What's so Transparent About Transparency?" Philosophical Studies 115: 225-244.

Kriegel, U. 2003. "Consciousness as Sensory Quality and as Implicit Self-Awareness." Phenomenology and the Cognitive Sciences 2 (1): 1-26.

Kriegel, U. 2009. Subjective Consciousness: A Self-Representational Theory. Oxford: Oxford University Press.

Lang, R. 2003. Seeing Who You Really Are: A Modern Guide to Your True Identity. Revised ed. London: The Shollond Trust, 2012.

Lusthaus, D. 2014. Buddhist Phenomenology: A Philosophical Investigation of Yogacara Buddhism and the Ch'eng Wei-shih Lun. London: Routledge.

Mackenzie, M. D. 2007. "The Illumination of Consciousness: Approaches to Self-Awareness in the Indian and Western Traditions." Philosophy East and West 57 (1): 40-62. 
Mackenzie, M. D. 2017. "Luminous Mind: Self-Luminosity Versus Other-Luminosity in Indian Philosophy of Mind." In Indian Epistemology and Metaphysics, edited by J. Tuske, 335-353. New York: Bloomsbury Academic.

Martin, M. G. F. 2002. “The Transparency of Experience." Mind and Language 17 (4): 376425.

Metzinger, T. 2003. Being No One: The Self-Model Theory of Subjectivity. Cambridge: The MIT Press.

Metzinger, T. 2017. "The Problem of Mental Action - Predictive Control Without Sensory Sheets." In Philosophy and Predictive Processing, edited by T. Metzinger and W. Wiese, 1-26. Frankfurt am Main: MIND Group.

Montague, M. 2016. The Given: Experience and Its Content. New York: Oxford University Press.

Moore, G. E. 1903. "The Refutation of Idealism." Mind: A Quarterly Review of Psychology and Philosophy 12: 433-453.

Nida-Rümelin, M. 2014. "Basic Intentionality, Primitive Awareness and Awareness of Oneself." In Mind, Values, and Metaphysics, edited by A. Reboul, 261-290. Cham: Springer.

Pace, M. 2007. "Blurred Vision and the Transparency of Experience." Pacific Philosophical Quarterly 88 (3): 328-354.

Padmasambhava, and Lingpa , K.. 2013. The Tibetian Book of the Dead. Berkeley: North Atlantic Books.

Peacocke, C. 1992. A Study of Concepts. Cambridge, MA: The MIT Press.

Pitt, D. 2004. "The Phenomenology of Cognition or What Is it Like to Think that P?" Philosophy and Phenomenological Research 69: 1-36.

Ramm, B. J. 2017. "Self-Experience." Journal of Consciousness Studies 24 (11-12): 142166.

Ramm, B. J. 2018. "First-person Experiments: A Characterisation and Defence." Review of Philosophy and Psychology. doi:10.1007/s13164-018-0388-1.

Sartre, J.-P. 1957. The Transcendence of the Ego: An Existentialist Theory of Consciousness. New York: Hill and Wang, 1991.

Schwitzgebel, E. 2011. Perplexities of Consciousness. Cambridge, MA: MIT Press.

Shear, J. 1998. "Experiential Clarification of the Problem of Self." Journal of Consciousness Studies 5 (5-6): 673-686.

Shear, J., and R. Jevning. 1999. "Pure Consciousness: Scientific Exploration of Meditation Techniques." Journal of Consciousness Studies 6 (2-3): 189-210.

Shoemaker, S. 1996. "Qualia and Consciousness." In The First-Person Perspective and Other Essays, 97-120. Cambridge: Cambridge University Press.

Siegel, S. 2007. "How Can We Discover the Contents of Experience?" The Southern Journal of Philosophy 45 (S1): 127-142.

Siewert, C. 1998. The Significance of Consciousness. Princeton, NJ: Princeton University Press.

Siewert, C. 2004. "Is Experience Transparent?" Philosophical Studies: An International Journal for Philosophy in the Analytic Tradition 117 (1-2): 15-41.

Skorupski, T. 2012. "Consciousness and Luminosity in Indian and Tibetan Buddhism." Paper presented at the 2nd IABU Conference, Buddhist Philosophy and Meditation Practice, 31 May-2 June, in Ayutthaya, Thailand. 
Speaks, J. 2009. "Transparency, Intentionalism, and the Nature of Perceptual Content." Philosophy and Phenomenological Research 79 (3): 539-573.

Stace, W. 1961. Mysticism and Philosophy. London: Macmillan.

Stoljar, D. 2004. "The Argument from Diaphanousness." Canadian Journal of Philosophy 30: 341-390.

Strawson, G. 1994. Mental Reality. Cambridge, MA: MIT Press.

Strawson, G. 2011. "Radical Self-Awareness." In Self, no Self? Perspectives from Analytical, Phenomenological, and Indian Traditions, edited by M. Siderits, E. Thompson, and D. Zahavi, 274-307. Oxford: Oxford University Press.

Strawson, G. 2015. "Self-Intimation." Phenomenology and the Cognitive Sciences 14 (1): $1-31$.

Thompson, E. 2014. Waking, Dreaming, Being: Self and Consciousness in Neuroscience, Meditation, and Philosophy. New York: Columbia University Press.

Thompson, E. 2015. "Dreamless Sleep, the Embodied Mind, and Consciousness - The Relevance of a Classical Indian Debate to Cognitive Science." In Open Mind: 37(T), edited by T. Metzinger and J. M. Windt, 1-19. Frankfurt am Main: MIND Group.

Tye, M. 1992. "Visual Qualia and Visual Content." In The Contents of Experience, edited by T. Crane, 158-176. Cambridge: Cambridge University Press.

Tye, M. 1995. Ten Problems of Consciousness. Cambridge, MA: The MIT Press.

Tye, M. 2002. "Representationalism and the Transparency of Experience." Nous 36 (1): 137-151.

Tye, M. 2003. Consciousness and Persons: Unity and Identity. Cambridge, MA: MIT Press. Tye, M. 2014. "Transparency, Qualia Realism and Representationalism." Philosophical Studies 170 (1): 39-57.

Windt, J. M. 2015. "Just in Time - Dreamless Sleep Experience as Pure Subjective Temporality - A Commentary on Evan Thompson." In Open Mind: 37(c), edited by T. Metzinger and J. M. Windt, 1-34. Frankfurt am Main: MIND Group.

Windt, J. M., T. Nielsen, and E. Thompson. 2016. "Does Consciousness Disappear in Dreamless Sleep?" Trends in Cognitive Sciences 20 (12): 871-882.

Zahavi, D. 2005. Subjectivity and Selfhood: Investigating the First-Person Perspective. Cambridge, MA: The MIT press.

Zahavi, D., and U. Kriegel. 2015. "For-me-ness: What It Is and What It Is Not." In Philosophy of Mind and Phenomenology: Conceptual and Empirical Approaches, edited by D. O. Dahlstrom, A. Elpidorou, and W. Hopp, 36-53. London: Routledge. 